\title{
PREDICTING THE IMPACT OF CLIMATE CHANGE ON THE DISTRIBUTION OF Flindersia pimenteliana F. Muell. IN INDONESIAN PAPUA AND PAPUA NEW GUINEA
}

\author{
IYAN ROBIANSYAH \\ Center for Plant Conservation Bogor Botanic Garden, Indonesian Institute of Sciences, \\ Bogor 16003, Indonesia
}

Received 12 December 2015/Accepted 12 August 2016

\begin{abstract}
Population of Flindersia pimenteliana (Maple Silkwood) in Indonesian Papua and Papua New Guinea is severely fragmented and experiencing a continuing decline due to habitat destruction and illegal logging. This species is very susceptible to environmental changes and at greater risk of extinction due to its small and fragmented geographic ranges and low abundance. Using maximum entropy (MaxEnt) method, the present study predicted the impact of climate change on the distribution of the species across its native distribution area. Elevation and 19 bioclimatic variables commonly used in species distribution modeling were used as predictors. The prediction model of the current potential distribution identified a total area of 156,214 $\mathrm{km}^{2}$ in Indonesian Papua and Papua New Guinea (18\% of total land area) as suitable habitat for F. pimenteliana. Elevation and precipitation of the wettest, coldest and warmest quarters contributed most to the model. Based on the average of HadGEM2-ES and MIROC-ESM models, potential distribution projections under RCP8.5 scenario suggested a habitat gain of 16\% for 2050 and 8\% for 2070 in the species distribution. Whereas under RCP4.5, an average habitat gain of 7\% was predicted for both 2050 and 2070 . The newly suitable habitats were predicted to be found mainly in Southern and Western Highland of Papua New Guinea. Protection of these areas from habitat destruction and land use change is needed to assist F. pimenteliana find the most suitable climate for its survival.
\end{abstract}

Keywords: Climate change, distribution models, Flindersiapimenteliana, MaxEnt, prediction

\section{INTRODUCTION}

Climate is one of the most important factors influencing plant distribution. At population scale, seed germination, growth and survival of plants are strongly influenced by temperature and precipitation (Walck et al. 2011). Thus, the rapidly changing climate for the coming decades will undoubtedly alter local environment where plants grow and consequently change their abundance and distribution (IPCC 2013). Plants have only two alternatives in dealing with future climate change in order to survive i.e. either adapting in situ or dispersing to find the most suitable climate for their survival. Failing to find the most suitable environment will result in the extinction of the plants. In this context, understanding and predicting the response of plant species and

\footnotetext{
* Corresponding author: iyan.robiansyah@lipi.go.id
}

possible distribution alternatives under climate change condition are important to develop proactive strategies to reduce the impact of climate change on plant species diversity.

Species Distribution Models (SDMs) is an important tool in ecology and biodiversity conservation, both for understanding the factors that affect species distribution and for predicting the response of species to climate change (Peterson et al. 2011; Franklin 2013; Guisan et al. 2013; Guillera-Arroita et al. 2015). These models correlate species occurrence data and environmental variables to estimate species distribution using statistical- or machine-learning procedures (Phillips et al. 2006; Roberts \& Hamann 2012). Among available models, Maximum Entropy (MaxEnt) (Phillips et al. 2006) is one of the best SDMs for analyzing the presence-only data in terms of ability to distinguish between areas where a species is 
present, versus those where it is absent (Elith et al. 2006). With more than 1,000 applications since 2006, MaxEnt is also one of the most popular SDMs, mainly due to the user-friendliness of the software and its high predictive accuracy compared to other SDMs (Merow et al. 2013).

Flindersia pimenteliana F. Muell. (Rutaceae) (Maple Silkwood) is a tree native to Queensland (Australia), Indonesian Papua and Papua New Guinea (Australian Tropical Rainforest Plants, http://keys.trin.org.au). The species is usually found in well developed rain forests and in various sites, but reaches its best development in upland and montane rain forests. Evaluation on population status of F. pimenteliana in Indonesian Papua and Papua New Guinea revealed that the tree is categorized as Endangered according to the International Union for Conservation of Nature (IUCN) Redlist Category and Criteria (Eddowes 1998). Illegal logging is identified as major threat for this species, leading to severe population fragmentation and decline in the population size. Such species is very sensitive to environmental changes and at greater risk of extinction. In this study, MaxEnt was used as a tool to predict the impact of climate change on the distribution of F. pimenteliana across its native environment. This study was aimed to: (1) predict current potential distribution of F. pimenteliana in Indonesian Papua and Papua New Guinea; (2) identify the environmental factors associated with habitat distribution of F. pimenteliana and (3) estimate the impact of climate change to the future potential distribution of the tree. The results of this study may serve as a basis in developing long term adaptation strategies for assisting $F$. pimenteliana in dealing with climate change.

\section{MATERIALS AND METHODS}

\section{Target Species and Occurrence Data}

Flindersia pimenteliana F. Muell. (synonym: F. chrysantha Merr. \& L.M. Perry and F. mazlini F.M. Bailey) (Rutaceae) is a tree having height up to 40 m. This plant species can be a canopy or subcanopy tree. Its habitat ranges from near sea level to $1,300 \mathrm{~m}$ asl. The tree has a straight, cylindrical trunk which can be unbranched for up to $20 \mathrm{~m}$ and its diameter can reach $100 \mathrm{~cm}$ (Conn \& Damas 2006). F. pimenteliana is heavily exploited from the wild due to its good quality timber, which is suitable for wood craft, furniture, moldings and interior construction purposes (Purnawati 2013). There had been several efforts to plant this tree in order to minimize timber harvesting from the wild. However, due to the trunk and canopy large sizes, it is economically impossible to grow this tree in plantation until reaching the same good timber quality as it is from the wild (Australian Tropical Rainforest Plants, http://keys.trin.org.au). Based on population assessment in Indonesian Papua and Papua New Guinea, the IUCN classifies F. pimenteliana as Endangered species, without considering population of this species in Queensland (Australia).

Occurrence data of F. pimenteliana were obtained from the Global Biodiversity Information Facility (GBIF) (www.gbif.org), an open access data portal that provides rich information about the known presence of organisms. A total of 74 records with geographical coordinate were initially obtained from GBIF. This low numbers of occurrences were mainly due to lack of occurrence information from Indonesian Papua. The data were then filtered for duplicate and autocorrelated occurrence points using spatially rarefy occurrence data tool in SDMtoolbox (Brown 2014). The tool removes spatial cluster of localities according to climate heterogeneity. For this purpose, the tool was set as having two classes, natural breaks classification type and $10 \mathrm{~km}$ minimum distance. The resulting data were composed of 23 unique distribution records which were then used for building the model. This filtering method can maximize the number of spatially independent localities and can enhance model performance by removing over-fit of the models towards environmental bias (Veloz 2009; Hijmans 2012; Boria et al. 2014).

\section{Creation of Bias File}

MaxEnt typically selects background points from a large area and compares them with the present data to differentiate between the suitable and unsuitable environmental conditions. Van Der Wal et al. (2009) showed that model 
performance was lower when background points were selected from a large area. This happened because the background points selected, which were very distant from all presence points, were more likely to show environmental conditions that were very different from those for the presence data (Anderson \& Raza 2010; BarbetMassin et al. 2012). Thus, the larger the study area, the higher proportion of less informative background points is included in the model. To overcome this problem, a bias file was created in the present study to restrict background point selection and hence, increase the model performance. Using buffered minimum-convex polygon tool in SDMtoolbox, the bias file was built with maximum radial distance of $10 \mathrm{~km}$ from the occurrence points.

\section{Selection of Environmental Variables}

The elevation and current bioclimatic data set was obtained from the Shuttle Radar Topography Mission (SRTM) global elevation data (http:// srtm.csi.cgiar.org/) and WorldClim 1.4 database (Hijmans et al. 2005; http:// www.worldclim.org), respectively. The current bioclimatic data (Nix 1986) consisted of 19 variables and were derived from monthly rainfall, while the temperature data were obtained from weather stations across the globe within the period of 1950 - 2000. These data showed annual trends, seasonality and extreme environmental factors; and were frequently used in predicting species distribution. Hence, a total of 20 environmental variables were initially considered for model building. All the environmental layers used in the model had 30 arc-seconds or $\approx 1 \mathrm{~km}$ resolution. These layers were clipped to the Indonesian Papua and Papua New Guinea political boundaries and then converted to ASCII raster files using ESRI ArcMap 10.1. Due to the limitation of data availability, the present study did not include other important variables influencing the distribution of plant species, such as soil characteristics, distance from water bodies and groundwater table.

To reduce model overfitting and minimize high co-linearity, highly correlated bioclimatic variables were removed from the model. For this purpose, pairwise Pearson correlation coefficient of current bioclimatic data was calculated using SDMtoolbox and $\mathrm{r} \leq \pm 0.9$ was used as a cut-off threshold to determine the exclusion of highly correlated variables (Table 1). The resulting variable set was composed of 9 predictors (Table 2).

Variables commonly used in ecological studies and best represented the original input of climate data (Bio1, Bio2, and Bio12) as well as those with the least correlation to others were retained in the model. Together with elevation data, these variables were considered to be the representatives of predictor candidates and were assessed through Maxent's jackknife test. As a consequence, variables that contributed $<1.0 \%$ were eliminated and the final explanatory variables obtained were then used to build MaxEnt models for F. pimenteliana (Table 2).

\section{Future Climate Projections}

To predict future distribution of F. pimenteliana, downscaled and calibrated global circulation model (GCM) of HadGEM2-ES (Hadley Centre Global Environment Model, version 2-Earth System) and MIROC-ESM (Model for Interdisciplinary Research on Climate-Earth System Models) for 2050 (average for 2041 - 2060) and 2070 (average for 2061 2080) were used (Hijmans et al. 2005; http://www.worldclim.org). These data were among the most recent GCM climate projections that were used in the Fifth Assessment Intergovernmental Panel on Climate Change (IPCC) Report. Each of these climate models had 30 arc-seconds resolution and projected two Representative Concentration Pathway (RCP) emission scenarios, namely RCP4.5 and RCP8.5. While the RCP4.5 represented low emission scenario, the RCP8.5 was a scenario of high greenhouse gas emissions and represented the worst case scenario of climate model simulation in the Fifth Assessment IPCC report (see Riahi et al. (2011) for more details of the scenarios). Final models for future habitat prediction were obtained by averaging results from HadGEM2-ES and MIROC-ESM future climate models. 


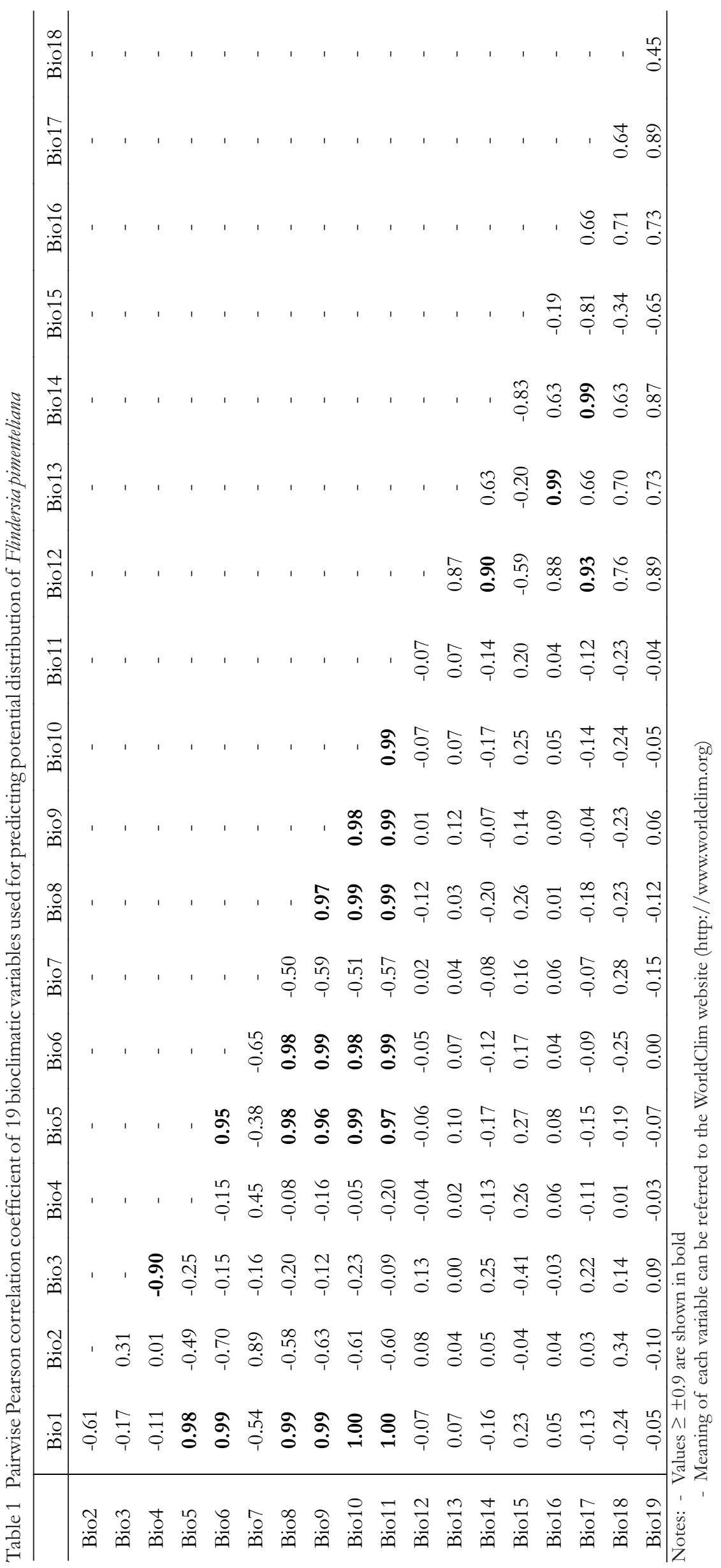




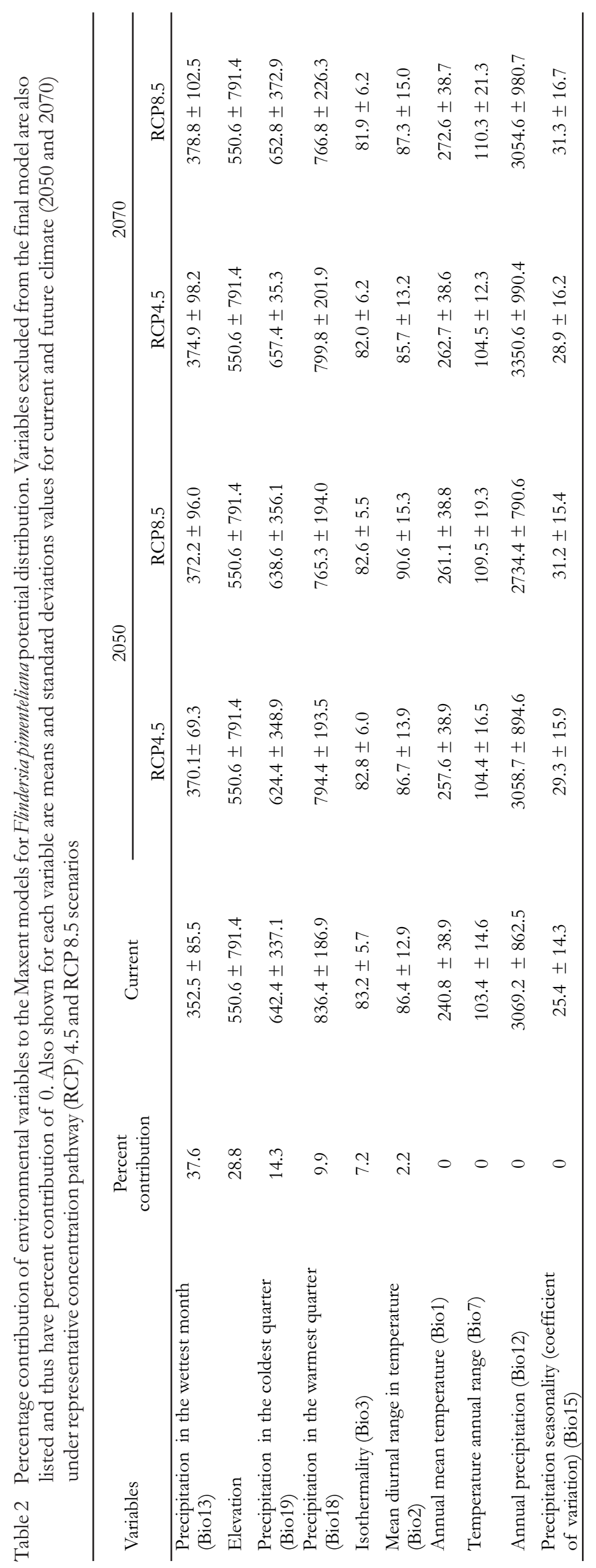


The potential range of loss and gain of F. pimenteliana was calculated for the year of 2050 and 2070. To determine whether the species assemblages would be constant or change in the future compared to the current potential habitats, the turnover rate $(T)$ was calculated using the following formula ( $\mathrm{Hu}$ et al. 2010):

$$
\mathrm{T}=100 \times \frac{\mathrm{G}+\mathrm{L}}{\mathrm{SR}+\mathrm{G}}
$$

$$
\begin{aligned}
& \text { where: } \mathrm{T}=\text { species turnover rate } \\
& \mathrm{G}=\text { species gain } \\
& \mathrm{L}=\text { species loss } \\
& \mathrm{SR}=\text { current species potential distribution }
\end{aligned}
$$

T value ranges from 0 to 100 , where value of 100 indicates that the species assemblages are different, while value of 0 indicates that the species assemblages are similar with previous conditions (Trisurat et al. 2011).

\section{Model Development and Evaluation}

The maximum entropy method, as implemented in MaxEnt (Version 3.3.3k), was used to model the potential distribution range of F.pimenteliana. To validate and calibrate the model, the MaxEnt modeling was run through Spatially Jackenife tool of SDMtoolbox. Model validation was done using geographically structured threefold cross-validation method. Furthermore, the tool tested different combinations of five model feature class types $(1=$ linear; $2=$ linear and quadratic; $3=$ hinge; $4=$ linear, quadratic, and hinge; and $5=$ linear, quadratic, hinge, product, and threshold) to optimize the model performance. Each of these model parameter classes was run in five replicates. Finally, the best model was automatically selected by evaluating the omission rate, Area Under the Curve (AUC) and model feature class complexity of each model. To measure the importance of environmental variables, the Spatially Jackeknife procedure was used which created response curves.

The best model selected was used to run the final model using all of the occurrence points. The model was also projected to the future climates of 2050 and 2070 using RCP4.5 and RCP8.5 emission scenarios. Maximum training sensitivity plus specificity logistic threshold was used to convert the continuous suitability index into suitable and unsuitable areas for F. pimenteliana.
The predicted suitable areas were then clipped by $25 \mathrm{~m}$ resolution PALSAR-2/PALSAR forest cover of 2015 obtained from the Japan Aerospace Exploration Agency (www.eorc.jaxa.jp).

\section{RESULTS AND DISCUSSION}

\section{Model Performance and Environmental Variable Responses}

Although there are some drawbacks attributed to MaxEnt, such as overfitting, model complexity dependency and independent evaluation data requirement (Radosavljevic \& Anderson 2014), its user-friendliness has attracted many application in SDMs. Furthermore, MaxEnt has been shown to perform better than other models for analyzing presence-only data. The model also has the best predictive power even with very low sample size (Wisz et al. 2008). In the present study, using 23 occurrence data, the MaxEnt model developed for predicting the potential distribution of $F$. pimenteliana was significantly better than random expectations. The average test AUC for the replicate runs was 0.710 (SD = 0.043). Peterson et al. (2011) argued that the AUC value of $0.7-0.9$ indicated moderate performance of the model. The present study was the first attempt on building SDMs to predict potential current and future distribution of F.pimenteliana in Indonesian Papua and Papua New Guinea.

After removing highly correlated bioclimatic variables and those with $<1 \%$ contribution, there were 6 variables identified as being important in creating model fit for F. pimenteliana (Table 2). Precipitation-related variables (Bio13, Bio18 and Bio19) had the most influence to F. pimenteliana distribution. These variables together contributed $61.8 \%$ to the model. On the other hand, temperature-related variables (Bio3 and $\mathrm{Bio} 2$ ) together contributed only $9.4 \%$ to the model. Furthermore, elevation was also important variable for F. pimenteliana distribution with $28.8 \%$ contribution. The significant role of precipitation on tree species distribution in tropical forests was well documented (Baltzer et al. 2008; BrenesArguedas et al. 2009; Baltzer \& Davies 2012). Soil water availability affected by precipitation is a direct determinant of tropical trees distributions in both local and regional scales (Engelbrecht et al. 2007; Toledo et al. 2012). 

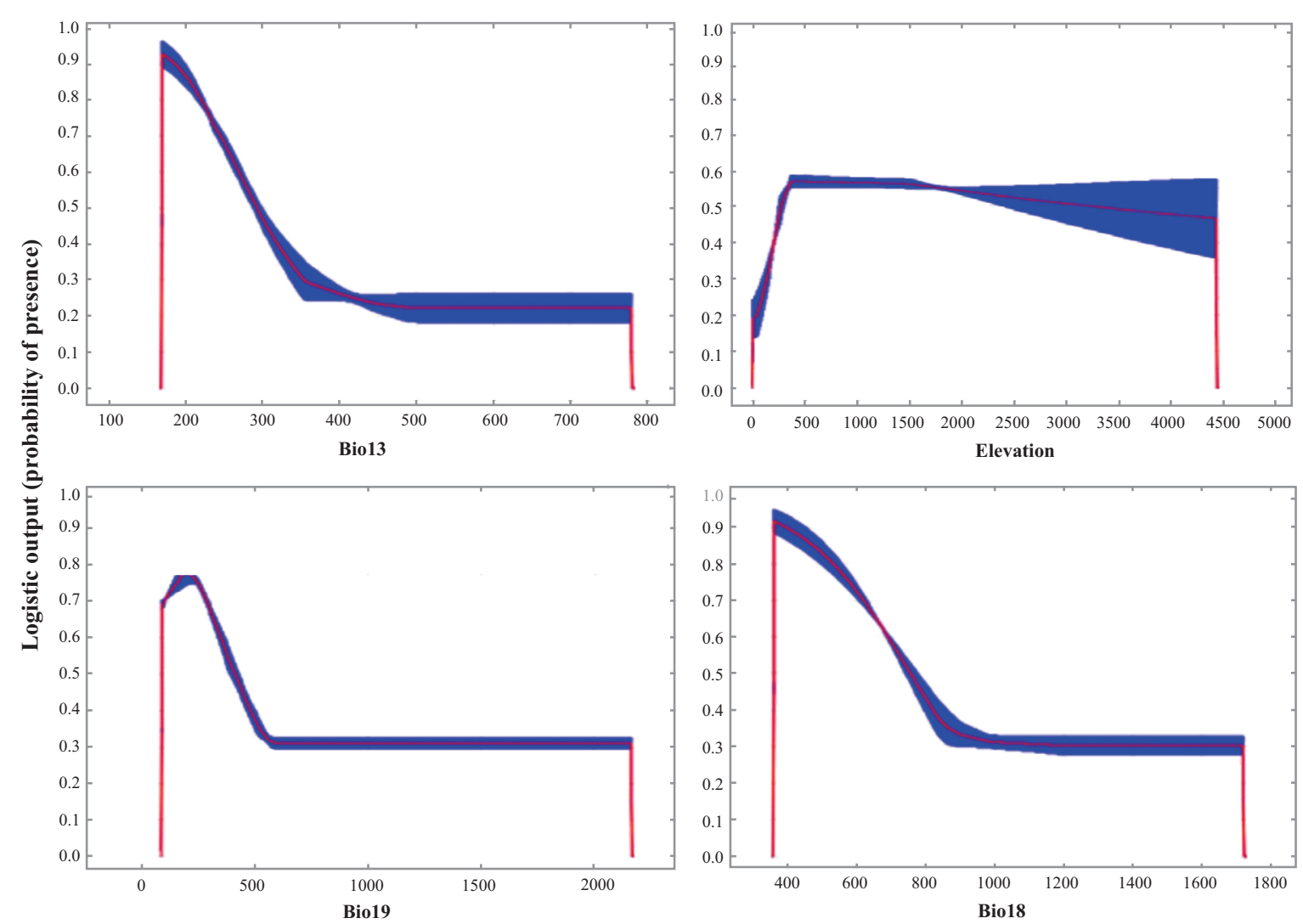

Figure 1 Response curves of the top four of highly contributed variables for MaxEnt model of Flindersia pimenteliana. The red center line represents the mean values derived from the cross-validation runs, while the blue curve delineates the standard deviation. Variable definitions: Bio13, elevation (m), Bio19 and Bio18 represent precipitation (mm) of the wettest month as well as the coldest and warmest quarters, respectively

Response curves of the top four of highly contributed variables for $F$. pimenteliana were shown in Figure 1. Habitats with elevation between 400 - 1,500 $\mathrm{m}$ had high potential suitability for the species. Furthermore, habitats with precipitation of the wettest month between 160 - $300 \mathrm{~mm}$ (Bio13) had high suitability for sustaining F. pimenteliana. In addition, the species preferred habitat having precipitation of the coldest quarter (Bio19) and the warmest quarter (Bio18) between $100-400 \mathrm{~mm}$ and $360-760 \mathrm{~mm}$, respectively. Habitat suitability of F. pimenteliana decreased with the increasing value of the precipitation-related variables. This pattern is understandable as, according to Schuur (2003), increased precipitation in humid tropical forests is known to have negative effect on plant growth and net primary productivity. The author argued that high rainfall in humid ecosystem may reduce plant growth and productivity by decreasing radiation inputs, increasing nutrient leaching or reducing soil oxygen availability.

\section{Prediction of Current Distribution}

Using maximum training sensitivity plus specificity logistic threshold (0.396), model prediction of the current distribution identified a total area of $156,214 \mathrm{~km}^{2}$ (18\% of total land area) as suitable habitat for F. pimenteliana. Liu et al. (2013, 2016) suggested that for presence-only data, maximum training sensitivity plus specificity logistic threshold can be used confidently for threshold selection as it produced higher sensitivity compared to other methods. Most of the suitable habitats were observed in mountainous regions and southern coastal areas of the main island where the precipitation intensity was relatively low (Fig. 2). In Indonesia, potentially suitable habitats for F. pimenteliana were mostly located along mountain chains of Indonesian Papua, extending from the mountain ranges in Sorong Regency to the Jayawijaya Mountains in Pegunungan Bintang Regency. There were also relatively separated suitable 


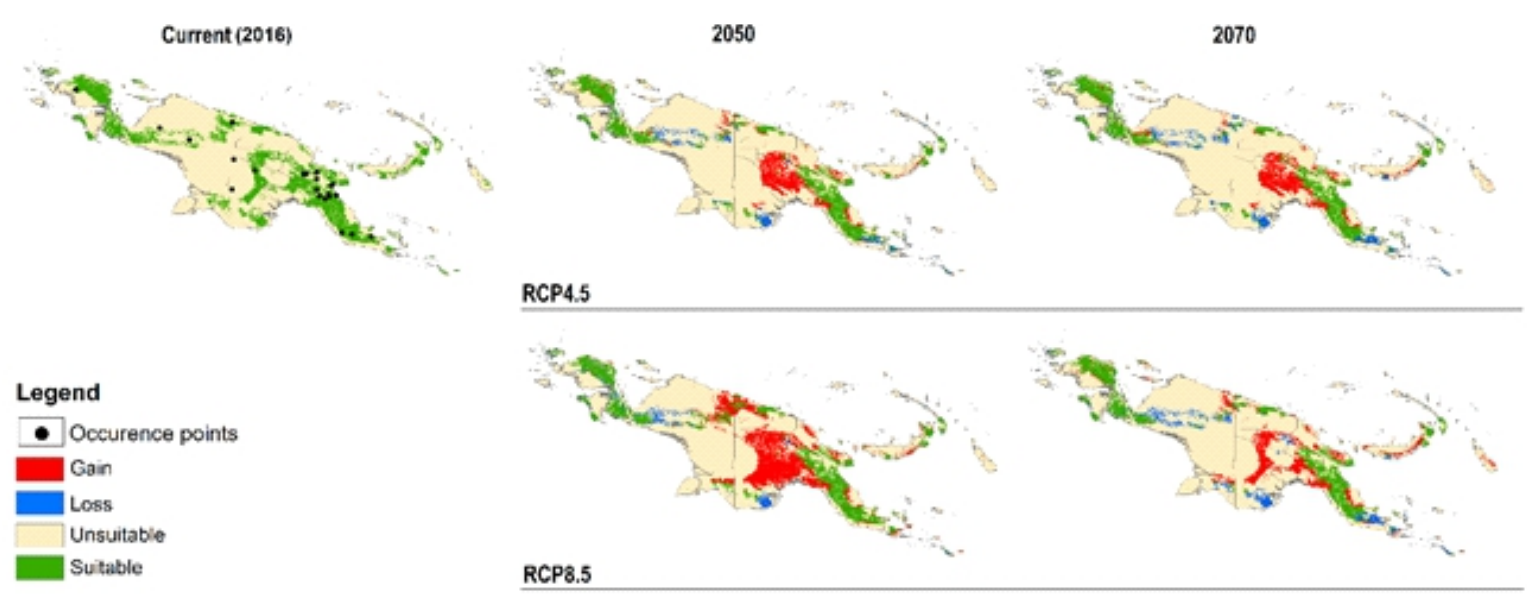

Figure 2 Predicted potential distribution of Flindersia pimenteliana for current (2016) and future climate conditions (2050 and 2070) under RCP4.5 and RCP8.5. Future habitat predictions were obtained by averaging results from HadGEM2-ES and MIROC-ESM future climate models

regions for F. pimenteliana such as in Waigeo Island in Raja Ampat Regency, Fakfak Mountains in Fakfak Regency, Kumawa Mountains in Kaimana Regency and coastal areas in the southern region of Merauke Regency. For Papua New Guinea, most of the potentially suitable habitats were observed to be along mountain regions in eastern highlands and Owen Stanley Range. Furthermore, suitable habitats were also detected in southwestern corner of the Western Province, coastal areas of East Sepik Province, east part of New Britain Island and New Ireland Island.

Very little is known about the habitat distribution of F. pimenteliana in Indonesia as study examining this species is very scarce. Recent study conducted by Purnawati et al. (2012) and Purnawati (2013) reported that the species was observed in Teluk Cendrawasih National Park, Teluk Wondama Regency, which was also included as a suitable habitat in the present model prediction. Further surveys in other predicted distribution areas of the plant are needed to validate the prediction of the present study.

For Papua New Guinea, some of the predicted areas agree with areas mentioned in the specimen records of $F$. pimenteliana held by the Royal Botanic Garden of Sydney (http://plantnet. rbgsyd.nsw.gov.au). These areas included many localities in Morobe Province (more than 53 records), Eilogo in Central Province, Bewani in West Sepik Province, Mount Obree and Toma Village in Northern Province, Mount Kilkerran and Rabaraba in Milne Bay Province and Goroko and Aiyura in Eastern Highlands Province. Further surveys are required in other predicted areas to validate the model prediction, especially in Western Province where specimen record of F. pimenteliana is absent. In addition, new surveys in previously known areas are also considered necessary as most of the records mentioned above are very old (some records are dated back to 1923).

Protected areas are one of the most important tools in plant conservation. In the present study, most of the predicted suitable habitats of F. pimenteliana were located outside the existing protected areas (Fig. 3). Only 24,393.9 km $(15.6 \%)$ of these habitats were currently covered by terrestrial protected areas in Indonesian Papua and Papua New Guinea. As can be seen in Figure 3 , protected areas with high coverage of predicted suitable habitats for F. pimenteliana are mostly found in Indonesia, including Tambrauw Mountain Nature Reserve, Lorenzt National Park, Jayawijaya Nature Reserve, Enarotali Nature Reserve and Kumawa Mountain Nature Reserve. To protect and conserve F. pimenteliana, expansion of existing protected areas or establishing the new one is necessary to cover the predicted suitable areas as much as possible. This action is especially needed in Papua New Guinea where only small percentage of the predicted suitable habitats is covered by the existing protected areas.

Although the present study was able to predict suitable habitats of F. pimenteliana with high success rate, care should be taken when implementing the results in the field-based conservation programs. Since MaxEnt estimates the fundamental niche of a species, the predicted distribution presented in this study might be 


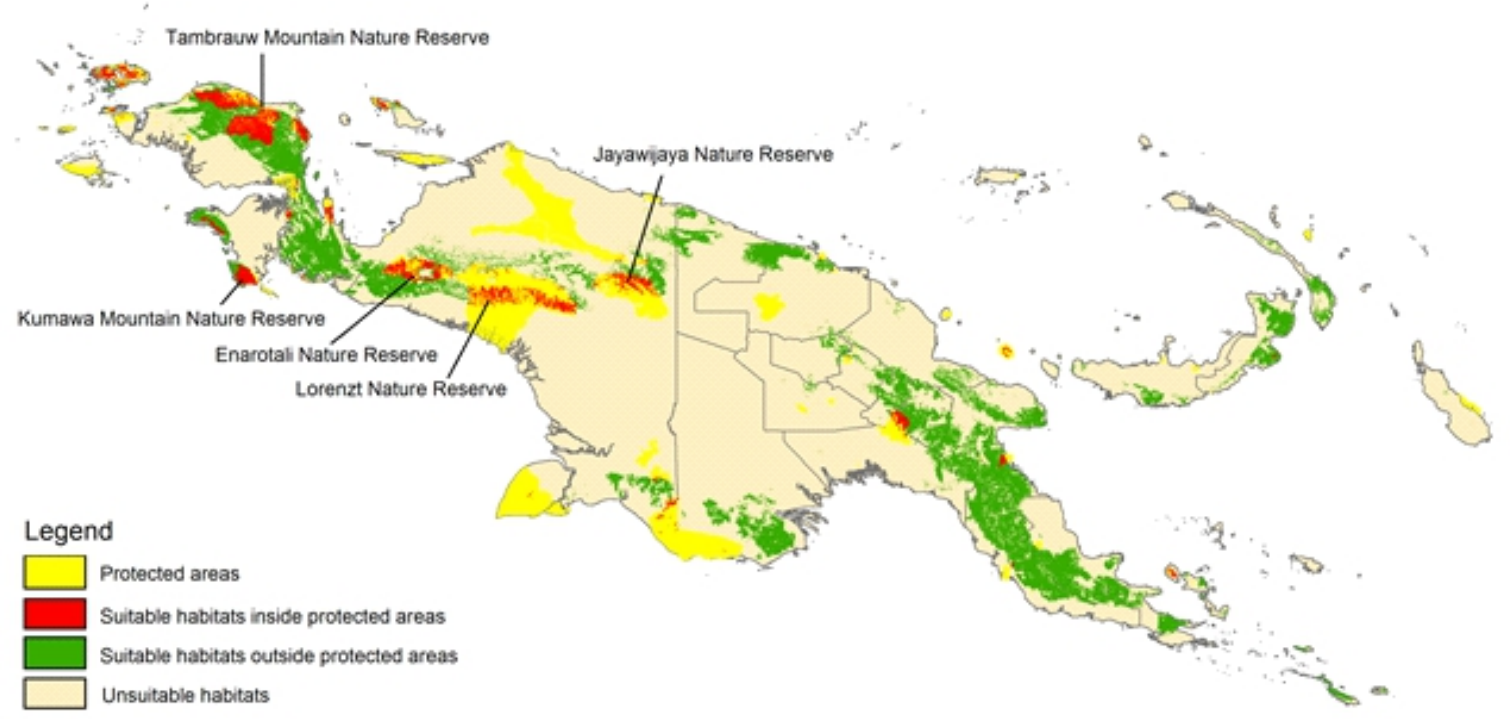

Figure 3 Current (2016) potential distribution of Flindersia pimenteliana and existing protected areas in Papua and Papua New Guinea according to World Database on Protected Areas (WDPA, http://www.protectedplanet.net/)

2050

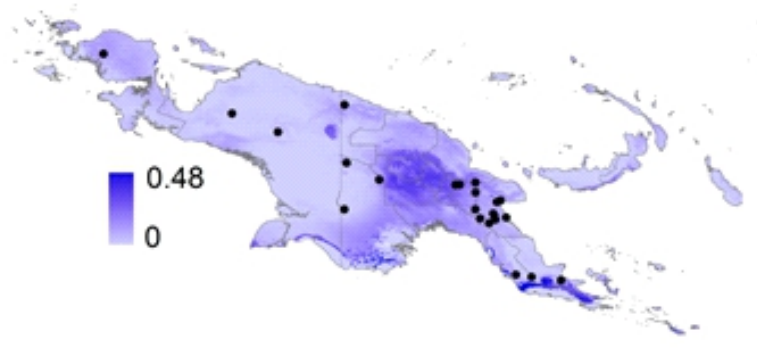

RCP4.5
2070

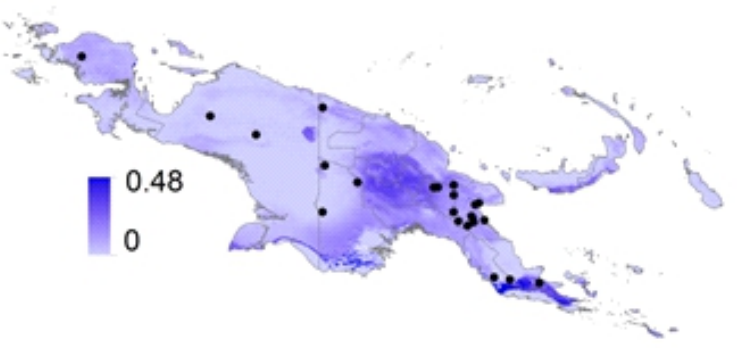

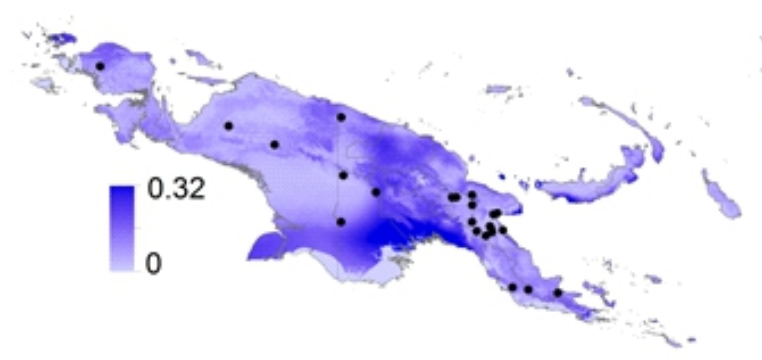

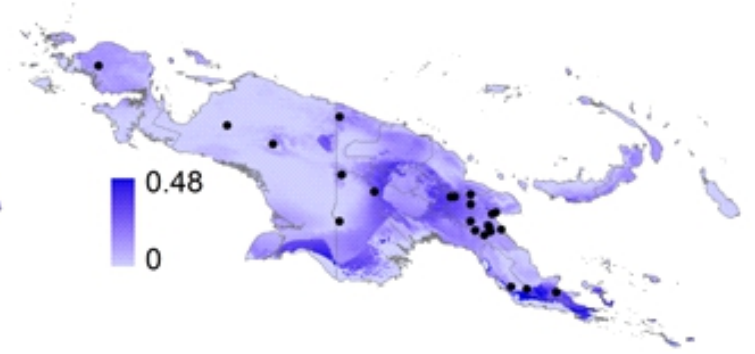

RCP8.5

Figure 4 Standard deviation of predicted probabilities of Flindersia pimenteliana occurrence from HadGEM2-ES and MIROC-ESM future climate models. Black dots are occurrence data used in modeling

overestimated (Pearson 2007). The model does not consider other factors influencing the distribution of plant species such as dispersal process, anthropogenic influences, biotic interactions or geographic barriers (Pearson 2007; Soberón 2007).

\section{Prediction of Future Distribution}

Future distribution of F. pimenteliana predicted by HadGEM2-ES and MIROC-ESM model generally had low agreement in Papua New Guinea compared to that in Indonesian Papua. Standard deviation between the two models was 
Table 3 Predicted gain, loss and total suitable habitats, and turnover rate of Flindersia pimenteliana for future climate conditions (2050 and 2070) under representative concentration pathway (RCP) 4.5 and RCP 8.5

\begin{tabular}{lcccc}
\hline & \multicolumn{3}{c}{2050} & \multicolumn{2}{c}{2070} \\
\cline { 2 - 5 } & RCP4.5 & RCP8.5 & RCP4.5 & RCP8.5 \\
\hline Suitable $\left(\mathrm{km}^{2}\right)$ & 195,058 & 275,956 & 188,578 & 190,397 \\
Gain $\left(\mathrm{km}^{2}\right)$ & 64,516 & 140,551 & 64,818 & 71,940 \\
Loss $\left(\mathrm{km}^{2}\right)$ & 25,671 & 20,810 & 32,454 & 37,757 \\
Turnover $(\%)$ & 41 & 54 & 44 & 48 \\
\hline
\end{tabular}

higher in Papua New Guinea, especially in regions where no sample data were recorded (Fig. 4). Based on the average value of the models, the suitable habitat for F. pimenteliana was predicted to decline by 3\% for RCP 4.5 and 2\% for RCP 8.5 in the year 2050. The suitable habitat gains for the two RCPs were $7 \%$ and $16 \%$, respectively. Hence, the percentage turnover in 2050 was estimated to be $41 \%$ and $54 \%$ for RCP4.5 and RCP 8.5 , respectively (Table 3).

For 2070, the suitable habitat for the species was predicted to decline by $4 \%$ for both RCP4.5 and RCP8.5, whereas the habitat gains were $7 \%$ and $8 \%$, respectively. Therefore, the percentage turnover in 2070 was estimated to be $44 \%$ for RCP4.5 and 48\% for RCP8.5 (Table 3). Under RCP4.5, the species was predicted to gain suitable habitats in Southern and Western Highland of Papua New Guinea in 2050. This gain was relatively stable and still could be observed in 2070. Higher suitable habitat gain was observed under RCP8.5 in 2050. This gain, however, was not stable and greatly decreased in 2070 (Fig. 2). In contrast, the suitable habitat along Jayawijaya Mountains, coastal area of Merauke Regency and East Sepik Province, and the most east of Owen Stanley Range in Papua New Guinea were predicted to disappear in 2050. These habitat losses were similar for both RCPs and relatively stable until 2070 (Fig. 2).

Since the species had turnover rate of more than $30 \%$, major shift in distribution was predicted to occur in the future for both RCPs. While some of predicted suitable habitats in southern coastal regions disappeared, mountainous areas located in the middle of Papua New Guinea were predicted to become suitable habitats for F. pimenteliana in 2050 and 2070. Changes in timing and seasonality of rainfall in the future may be responsible for this range shift. Australian Bureau of
Meteorology and CSIRO (2011) predicted rainfall pattern change in Papua New Guinea with more than $15 \%$ increase in annual and seasonal rainfall by 2090 . This range shift of geographic distribution towards higher elevation is also observed in many terrestrial organisms and is commonly linked to increased growth and dispersal success due to warmer climate (Chen $e t$ al. 2011). Although the temperature was predicted to increase at $0.11{ }^{\circ} \mathrm{C}$ per decade over Papua New Guinea (Australian Bureau of Meteorology and CSIRO 2011) and in the range of $0.2-0.3^{\circ} \mathrm{C}$ per decade over Indonesian Papua (Boer \& Faqih 2004), the present study, however, was unable to detect this correlation as all temperature-related variables had little effect to the model.

\section{CONCLUSIONS}

It is likely that F. pimenteliana will benefit from climate change, as environmentally suitable ranges for this species are projected to increase by 2050 and 2070. The present study predicted major range shift of geographic distribution for the species towards higher elevation. The newly suitable habitats were predicted to be found mainly in Southern and Western Highland of Papua New Guinea. These are the areas where the protection of the species might be the most feasible and cost-effective in the future. Thus, protection of these areas from habitat destruction and land use changes is needed to make sure that F. pimenteliana can adapt to the climate change. Further field surveys are required to validate the prediction of the present study. Furthermore, it is recommended to obtain additional occurrence data and include other important predictors (e.g. edaphic factors) to minimize uncertainty in climate projections. 


\section{REFERENCES}

Anderson RP, Raza A. 2010. The effect of the extent of the study region on GIS models of species geographic distributions and estimates of niche evolution: preliminary tests with montane rodents (genus Nephelomys) in Venezuela. J Biogeogr 37:1378-93.

Australian Bureau of Meteorology, CSIRO. 2011. Climate change in the Pacific: scientific assessment and new research. Volume 2: Country Reports. Available from: http://www. pacificclimatechangescience.org/wp-content/ uploads/2013/09/Papua-New-Guinea.pdf. Retrieved on 16 August 2016.

Baltzer JL, Davies SJ. 2012. Rainfall seasonality and pest pressure as determinants of tropical tree species' distributions. Ecol Evol 2(11):2682-94.

Baltzer JL, Davies SJ, Bunyavejchewin S, Noor NSM. 2008. The role of desiccation tolerance in determining tree species distributions along the Malay-Thai Peninsula. Funct Ecol 22:221-31.

Barbet-Massin M, Jiguet F, Albert CH, Thuiller W. 2012. Selecting pseudoabsences for species distribution models: how where and how many? Methods Ecol Evol 3:327-38.

Boer R, Faqih A. 2004. Current and future rainfall variability in Indonesia. In: Lasco RD, Boer R, editors. An integrated assessment of climate change impacts, adaptation and vulnerability in watershed areas and communities in Southeast Asia. Report from AIACC Project No. AS21 (Annex C, p.95-126). Washington, District of Columbia (US): International START Secretariat.

Boria RA, Olson LE, Goodman SM, Anderson RA. 2014. Spatial filtering to reduce sampling bias can improve the performance of ecological niche models. Ecol Model 275:73-7.

Brenes-Arguedas T, Coley PD, Kursa TA. 2009. Pests vs. drought as determinants of plant distribution along a tropical rainfall gradient. Ecology 90(7):1751-61.

Brown JL. 2014. SDMtoolbox: a python-based GIS toolkit for landscape genetic, biogeographic, and species distribution model analyses. Methods Ecol Evol 5(7):694-700.

Chen IC, Hill JK, Ohlemüller R, Roy DB, Thomas CD. 2011. Rapid range shifts of species associated with high levels of climate warming. Science 333:1024-6.

Conn BJ, Damas KQ. 2006. Guide to trees of Papua New Guinea. Available from: http:/ /www.pngplants.org/ PNGtress. Retrieved on 16 August 2016.

Eddowes PJ. 1998. Flindersiapimenteliana. The IUCN Red List of Threatened Species. Version 2014.3. Available from: www.iucnredlist.org. Retrieved on 16 April 2016.

Elith J, Graham CH, Anderson RP, Dudik M, Ferrier S, Guisan A, Hijmans RJ, Huettmann F, Leathwick JR,
Lehmann A, Li J, Lohmann LG, Loiselle BA, Manion G, Moritz C, Nakamura M, Nakazawa Y, Overton JMM, Peterson AT, Phillips SJ, Richardson K, Scachetti-pereira R, Schapire RE, Soberón J, Williams S, Wisz SM, Zimmermann NE. 2006. Novel methods improve prediction of species' distributions from occurrence data. Ecography 29:129-51.

Engelbrecht BMJ, Comita LS, Condit R, Kursar TA, Tyree MT, Turner BL, Shubbell SP. 2007. Drought sensitivity shapes species distribution patterns in tropical forests. Nature 447:80-2.

Franklin J. 2013. Species distribution models in conservation biogeography: developments and challenges. Divers Distrib 19:1217-23.

Guillera-Arroita G, Lahoz-Monfort JJ, Elith J, Gordon A, Kujala H, Lentini PE, McCarthy MA, Tingley R, Wintle BA. 2015. Is my species distribution model fit for purpose? Matching data and models to applications. Global Ecol Biogeogr 24:276-92.

Guisan A, Tingley R, Baumgartner JB, Naujokaitis-Lewis I, Sutcliffe PR, Tulloch AIT, Regan TJ, Brotons L, McDonald-Madden E, Mantyka-Pringle C, Martin TG, Rhodes JR, Maggini R, Setterfield SA, Elith J, Schwartz MW, Wintle BA, Broennimann O, Austin M, Ferrier S, Kearney MR, Possingham HP, Buckley YM. 2013. Predicting species distributions for conservation decisions. Ecol Lett 16:1424-35.

Hijmans RJ, Cameron SE, Parra JL, Jones PG, Jarvis A. 2005. Very high resolution interpolated climate surfaces for global land areas. Int J Climatol 25:196578.

Hijmans RJ. 2012. Cross-validation of species distribution models: removing spatial sorting bias and calibration with a null model. Ecology 93:679-88.

Hu J, Hu H, Jiang Z. 2010. The impacts of climate change on the wintering distribution of an endangered migratory bird. Oecologia 164:555-65.

IPCC [Intergovernmental Panel on Climate Change]. 2013. Climate change 2013: the physical science basis. Stocker TF, Qin D, Plattner GK, Tignor M, Allen SK, Boschung J, et al., editors. Contribution of Working Group I to the Fifth Assessment Report of the Intergovernmental Panel on Climate Change. Cambridge (UK): Cambridge University Press. $1535 \mathrm{p}$.

Liu C, Newell G, White M. 2016. On the selection of thresholds for predicting species occurrence with presence-only data. Ecol Evol 6(1):337-48.

Liu C, White M, Newell G. 2013. Selecting thresholds for the prediction of species occurrence with presenceonly data. J Biogeogr 40(4):778-89.

Merow C, Smith MJ, Silander JA. 2013. A practical guide to MaxEnt for modeling species' distributions: what it does, and why inputs and settings matter. Ecography 36:1058-69. 
Nix HA. 1986. A biogeographic analysis of Australian elapid snakes. In: Longmore R, editor. Atlas of Elapid Snakes of Australia. Australian Flora and Fauna Series Number 7. Canberra (AU): Australian Government Publishing Service. p. 4-15.

Pearson RG. 2007. Species distribution modeling for conservation educators and practitioners. Synthesis. New York (US): American Museum of Natural History. Available from: http://ncep.amnh.org. Retrieved on 11 November 2015.

Peterson AT, Soberón J, Pearson RG, Anderson RP, Martínez-Meyer E, Nakamura M, Araújo M. 2011. Ecological niches and geographic distributions. New Jersey (US): Princeton University Press. 328 p.

Phillips SJ, Anderson RP, Schapire RE. 2006. Maximum entropy modeling of species geographic distributions. Ecol Model 190:231-59.

Purnawati R, Wahyudi I, Priadi T. 2012. Anatomical properties of Flindersia pimenteliana F. Muell from Wondama Bay West Papua. Jurnal Ilmu dan Teknologi Kayu Tropis 10(2):122-9.

Purnawati R. 2013. Basic and processing properties of maniani (Flindersiapimenteliana F. v. Muell) wood from Wondama Bay, West Papua. Master Thesis. Bogor (ID): Bogor Agricultural University. 65 p.

Radosavljevic A, Anderson RP. 2014. Making better Maxent models of species distributions: complexity, overfitting and evaluation. J Biogeogr 41(4):629-43.

Riahi K, Rao S, Krey V, Cho C, Chirkov V, Fischer G, Kindermann G, Nakicenovic N, Rafaj P. 2011. RCP 8.5-A scenario of comparatively high greenhouse gas emissions. Clim Change 109:33-57.

Roberts DR, Hamann A. 2012. Predicting potential climate change impacts with bioclimate envelope models: a palaeoecological perspective. Glob Ecol Biogeogr 21(2):121-33.

Schuur EAG. 2003. Productivity and global climate revisited: the sensitivity of tropical forest growth to precipitation. Ecology 84(5):1165-70.

Soberón J. 2007. Grinnellian and Eltonian niches and geographic distributions of species. Ecol Lett 10:1115-23.

Toledo M, Pena-Claros M, Bongers F, Alarcon A, Balcazar J, Chuvina J, Leaño C, Licona JC, Poorter L. 2012. Distribution patterns of tropical woody species in response to climatic and edaphic gradients. J Ecol 100:253-63.

Trisurat Y, Shrestha RP, Kjelgren R. 2011. Plant species vulnerability to climate change in Peninsular Thailand. Appl Geogr 31:1106-14.

Van Der Wal J, Shoo LP, Graham C, Williams SE. 2009. Selecting pseudo-absence data for presenceonly distribution modeling: how far should you stray from what you know? Ecol Model 220(4): 589-94.

Veloz SD. 2009. Spatially autocorrelated sampling falsely inflates measures of accuracy for presence-only niche models. J Biogeogr 36:2290-9.

Walck JL, Hidayati SN, Dixon KW, Thompson K, Poschlod P. 2011. Climate change and plant regeneration from seed. Glob Change Biol 17:2145-61.

Wisz MS, Hijmans RJ, Li J, Peterson AT, Graham CH, Guisan A, Nceas Predicting Species Distributions Working Group. 2008. Effects of sample size on the performance of species distribution models. Divers Distrib 14:763-73. 